\title{
PV Based Grid System for Power Quality Enhancement using Instantaneous P-Q Theory
}

\author{
Suresh K. P., Ramesh S.
}

\begin{abstract}
The SPV interfaced grid system with battery storage unit, bidirectional VSI interconnected shunt active filter, an adaptive Proportional Integral (PI) controller is employed for improve current and voltage profile enhancement. The p-q theory is the common employed technique to extract the basic fundamental current harmonic components from affected or polluted power supply by means of diode rectifier or non linear load. The basic concepts of reactive power (IRP) theory includes it's a time domain model and it can be applicable for both $3 P 3 W$ and $3 P 4 W$. Initially, the control technique called instantaneous real and reactive power theory or $p-q$ theory has been developed for three phase three wire system and then later it was extend to three phase four wire system. This system is valid under steady state as well as dynamic state. The bidirectional VSI based shunt APF is controlled by the PI based instantaneous reactive power theory. The proposed PI Controller interfaced shunt Active Power Filter is used to maintain DC-Link voltage.SPV system is interfaced with incremental conductance MPPT algorithm. This SAPF control scheme has to provide the following benefits like current harmonic mitigation as well as reactive power compensation
\end{abstract}

Keywords: Solar photovoltaic system, Proportional Integral controller, $P-Q$ theory, $D C-D C$ boost converter, Current harmonics.

\section{INTRODUCTION}

Usage of non-linear loads such as power electronic devices, diodes, thyristor controlled rectifiers (TCR), uninterruptable power supplies (UPS), solid state drives, battery chargers, and house hold electronic components are increasing day by day. This frequent usage of electronic devices creates harmonic problem in distribution power network which reduces the power quality [1]. These loads directly inject harmonics into the power distribution network which directly affects the input voltage supply and source current at the distribution sector is not remains sinusoidal. The current harmonics related issues are reduced by various techniques like active, passive and hybrid filter with shunt and series for $1 \mathrm{P} 2 \mathrm{~W}$, $3 \mathrm{P} 3 \mathrm{~W}$ and $3 \mathrm{P} 4 \mathrm{~W}$ systems. The $3 \mathrm{P} 4 \mathrm{~W}$ system is mostly used in residential purpose, industrial and commercial sectors. The current harmonics in the power network reduces the efficiency of apparatus and creates major impacts like overheating of conductor, reduced power factor, vibrations in motor drives, voltage fluctuations, busting of capacitor, noise

Revised Manuscript Received on December 15, 2019

* Correspondence Author

K. P. Suresh, Department of Electrical and Electronics Engineering, Sri Krishna College of Technology,Kovaipudur, Coimbatore, Tamilnadu, India. Email: sureshkp@ skct.edu.in

S. Ramesh, Department of Electrical and Electronics Engineering, K.S.R. College of Engineering, Tiruchengode, Namakkal, Tamilnadu, India. Email: rameshksrce@gmail.com in the equipments and excessive neutral current. Moreover, the harmonics causes reduce the power factor in system which makes the major loss and this problem stated as main problem in power quality. These impacts especially reduce the expected life time and withstand capacity of the end user equipments connected at PCC.[2] Moreover it causes dangerous disturbances such as electromagnetic interference (EMI) and mal-functioning of meters associated with sensitive power electronic devices under continuous operation. In all modern industries, the automated controllers and energy efficient devices is used and it is very sensitive in power supply deviations also. Hence, the maintenance of power quality is very much essential based on these issues may occur in distribution network[3-8].

Harmonic issues are slightly reduced with passive filters in conventional method, but it's not providing the good results. The passive filter creates resonance problem, improper reactive power compensation and consumes more space when compared to active filter. The passive filters are not suitable for unbalanced supply and it's only applicable for specific load condition system [9-11]. The main advantage of active filter is easily adopts under dynamic load fluctuations and it plays major role in present compensation scenario [12].

\section{SYSTEM DESCRIPTION}

The active power filter is mostly recommended tradition power filtering device for reducing harmonic disturbances and to reactive power disturbances continuously even at unbalanced load changing condition. Shunt filter is interconnected at the junction called Point of Common Coupling (PCC) of the distribution network which injects the compensating SAPF current to minimize current harmonics by means of non linear loads (Salim \& Toufik et al 2001). Figure 1 exhibits the schematic diagram of 3 phase shunt active power filter (SAPF) connected with grid system. 


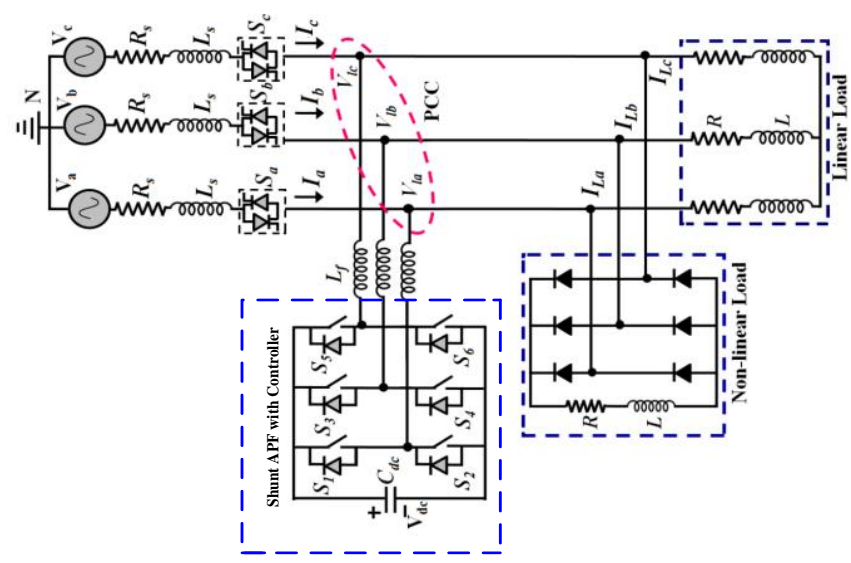

Fig 1. Schematic diagram of 3 phase shunt active power filter connected with grid system[13]

The effectiveness of the proposed system interfaced with Solar Photo Voltaic (SPV) system based shunt APF mainly based on which controlling type technique employed for generate compensation current through extended reference current signal generation strategy, compensation time, parameter consideration of the system to compensate and circuit connection( EI-Habrouk et al 2000). Commonly employed reference current signal generation strategies are $\mathrm{p}-\mathrm{q}$ theory. The proportional integral controller based $\mathrm{p}-\mathrm{q}$ theory is utilized to minimize above said power quality problems by injects the extracted compensated current signal at the point of PCC in grid system. The important aspect for compensation is to maintain constant capacitance voltage at DC side of VSI, $\mathrm{V}_{\mathrm{dc}}$ in the storage DC capacitor which supports the operation of Voltage Source Inverter (VSI) interconnected with SAPF. Due to addition of non-linear load or sudden changes affects the DC voltage of VSI magnitude directly which may above or below its fixed reference value.[14] The smooth operation of shunt active power filter requires constant magnitude DC-Link voltage, so the proportional integral (PI) controller based SAPF is employed to maintain the magnitude within the reference level for instantaneous reactive power theory[15].

PI controller is commonly used control technique because of its very simple implementation and computation features, the voltage error manipulation approach is utilized to find out the voltage difference between the desired reference voltage[16], $\mathrm{V}_{\mathrm{dcref}}$ and actual DC Link capacitor voltage, $\mathrm{V}_{\mathrm{dc}}$ by proportional integral controller. Hence, the entire performance of proportional integral controller is based on the tuned gain value of $\mathrm{K}_{\mathrm{p}}$ and $\mathrm{K}_{\mathrm{i}}$ parameter. Based on PI gain parameter, the proposed control scheme generate required reference current and maintain constant magnitude voltage across $\mathrm{C}_{\mathrm{dc}}$ (Direct current link capacitor) .To validate the effectiveness of available harmonics reduction and voltage disturbances are verified by simulation in MATLAB/Simulink.[17]

\section{CONTROL STRATEGY}

This proposed method used control strategy techniques is employed to retrive the fundamental harmonic component[13]. The preferred technique must be suitable for mainly two states such as stable (or steady state) and transient state condition [14-18]. In this section, steady state analysis and transient analysis is done with the help of Fast Fourier Transform (FFT) for the following control techniques. Fig 2

depicts the block diagram of 3PSAPF connected with grid system [19-20].

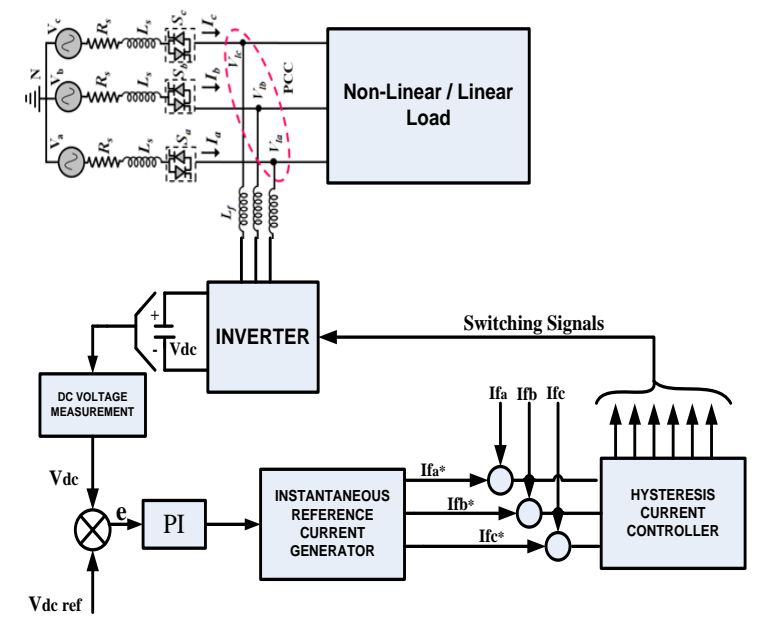

Fig 2. 3Phase - SAPF with grid system block diagram

From the source side, the voltages are represented as $\left(\mathrm{V}_{\mathrm{a}}, \mathrm{V}_{\mathrm{b}}\right.$, $\left.V_{c}\right)$ and currents are represented as $\left(I_{a}, I_{b}, I_{c}\right)$. Similarly the current at load side are considered as $\left(\mathrm{I}_{\mathrm{La}}, \mathrm{I}_{\mathrm{Lb}}, \mathrm{I}_{\mathrm{Lc}}\right)$. Parallel connected SAPF generates the current references (I*fa, I* $\mathrm{fb}$, $I^{*} \mathrm{fc}$ ) based on instantaneous reference current or p-q theory and fed into grid at PCC [21]. The performance of proportional integral SAPF controller is based on constant DC side VSI voltage and $p-q$ scheme is employed to compute the reference current and inject the suitable compensation current into grid[22].

\section{IV.COMPENSATION REFERENCE CURRENT GENERATION}

In this P-Q control scheme, first transforms three phase $a b c$ coordinates to $\alpha \beta 0$ coordinates by Clarke transformation, where $\alpha \beta$ represents orthogonal, and $O$ represents zero sequence component. After this algebraic transformation, then calculate active, $p$ and reactive power $q$. Reactive power must be compensate by undesirable component.[23]

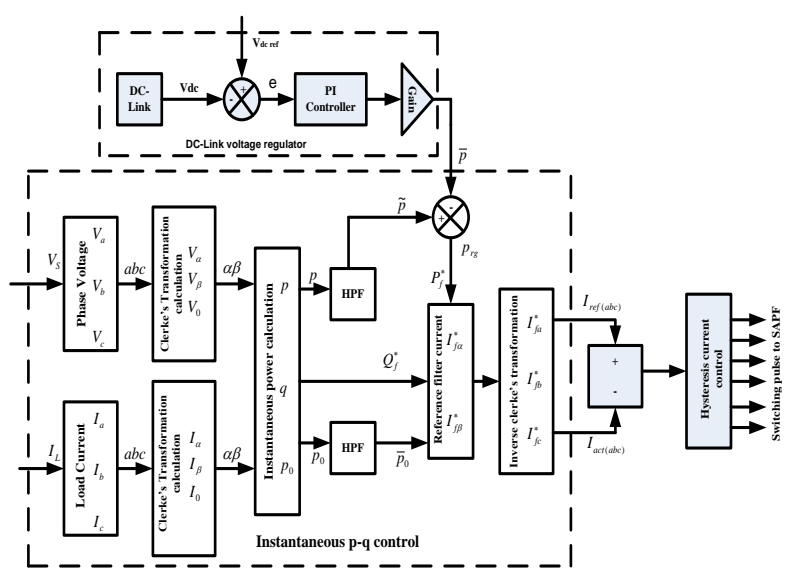

Figure 3. Proposed instantaneous p-q scheme

The proposed solar photovoltaic interfaced SAPF with proportional integral based $\mathrm{P}-\mathrm{Q}$ scheme is used to compensate the $3 \mathrm{P}$ load currents. 
Harmonics occur due to nonlinear loads and some power electronic switches in bidirectional VSI is filtered by the coupling inductance Lf. In Fig 3 depicts the designed PI SAPF with instantaneous p-q control technique where $\mathrm{I}_{\mathrm{fa}}{ }_{\mathrm{fa}}, \mathrm{I}_{\mathrm{fb}}{ }_{\mathrm{fb}}$, and $\mathrm{I}_{\mathrm{fc}}^{*}$ represents the reference current for all three phases(A,B and C)[22]. The actual current $\left(\mathrm{I}_{\mathrm{fa}}, \mathrm{I}_{\mathrm{fb}}, \mathrm{I}_{\mathrm{fc}}\right)$ and reference SAPF are given as input to constant frequency hysteresis current controller (HCC) which is employed to limit ripple current passes through the coupling inductor $\mathrm{L}_{\mathrm{f}}$. PI Controller interfaced shunt APF with p-q scheme.

This controller maintains injected current into the load distribution system. The instantaneous P-Q power components like active power (p) and reactive power (q) are regulated by the control signal generated from SAPF[19]. The input signal given to the PI based shunt APF controller are all $3 \mathrm{P}$ reference voltage and current in the distribution system. PI controller based DC side VSI voltage is employed to regulate magnitude at junction of DC side voltage between converter and shunt APF

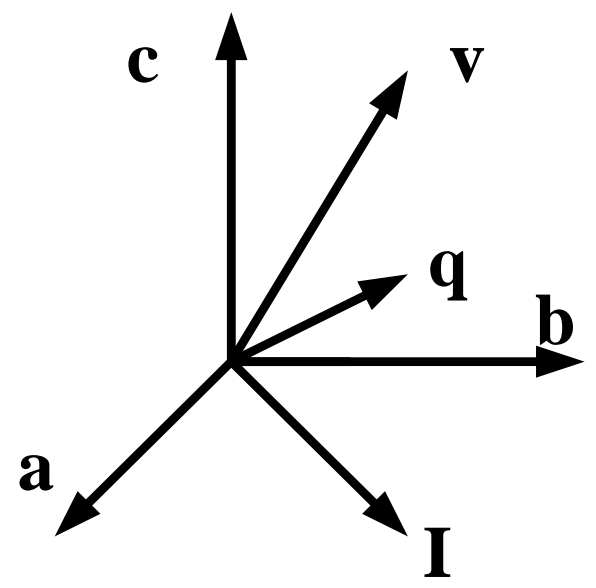

Figure.4 Three phase coordinates

Three phase coordinates are shown in the Figure .4 which represents all three phases mutually orthogonal in structure. The Instantaneous active (or real) and reactive ( or imaginary) power can be expressed as $\mathrm{p}$ and $\mathrm{q}$.

The source voltages $\left(\mathrm{V}_{\mathrm{a}}, \mathrm{V}_{\mathrm{b}}, \mathrm{V}_{\mathrm{c}}\right)$ and source currents $\left(\mathrm{I}_{\mathrm{a}}, \mathrm{I}_{\mathrm{b}}, \mathrm{I}_{\mathrm{c}}\right)$ are expressed the form of vectors as $\mathrm{V}$ and I respectively, that is

$$
\begin{gathered}
V=\left[\begin{array}{l}
V_{a} \\
V_{b} \\
V_{C}
\end{array}\right] \\
I=\left[\begin{array}{l}
I_{a} \\
I_{b} \\
I_{C}
\end{array}\right]
\end{gathered}
$$

The active power, $\mathrm{p}$ of the $3 \mathrm{P}$ circuit is expressed by clarke's transformation form as $(1 \& 2)$

$$
\begin{aligned}
& {\left[\begin{array}{l}
V_{0} \\
V_{\alpha} \\
V_{\beta}
\end{array}\right]=\sqrt{\frac{2}{3}}\left[\begin{array}{ccc}
\frac{1}{\sqrt{2}} & \frac{1}{\sqrt{2}} & \frac{1}{\sqrt{2}} \\
1 & -\frac{1}{2} & -\frac{1}{2} \\
0 & \frac{\sqrt{3}}{2} & -\frac{\sqrt{3}}{2}
\end{array}\right]\left[\begin{array}{l}
V_{a} \\
V_{b} \\
V_{c}
\end{array}\right]} \\
& {\left[\begin{array}{l}
I_{0} \\
I_{\alpha} \\
I_{\beta}
\end{array}\right]=\sqrt{\frac{2}{3}}\left[\begin{array}{ccc}
\frac{1}{\sqrt{2}} & \frac{1}{\sqrt{2}} & \frac{1}{\sqrt{2}} \\
1 & -\frac{1}{2} & -\frac{1}{2} \\
0 & \frac{\sqrt{3}}{2} & -\frac{\sqrt{3}}{2}
\end{array}\right]\left[\begin{array}{l}
I_{a} \\
I_{b} \\
I_{c}
\end{array}\right]}
\end{aligned}
$$

Where, $V_{0}$ and $V_{\alpha}, V_{\beta}$ represents zero sequence voltage and axis voltage respectively. It can be represented as in the following equations

$$
p=V_{\alpha} I_{\alpha}+V_{\beta} I_{\beta}
$$

$q=V_{\beta} I_{\alpha}-V_{\alpha} I_{\beta}$

The instantaneous active and reactive power consists of two components according to the equation $(5 \& 6)$

$$
\begin{aligned}
& p=\bar{p}+\tilde{p} \\
& q=\bar{q}+\tilde{q}
\end{aligned}
$$

Where the components, $\bar{p}$ and $\tilde{p}$ represents an average component of active power and zero mean oscillatory component, $\bar{q}$ and $\tilde{q}$ indicates the average and zero mean oscillatory internal components of the reactive power.

\section{PROPORTIONAL INTEGRAL CONTROLLER BASED SAPF}

Error signal, e is calculated with the difference value between the actual voltage, $\mathrm{V}_{\mathrm{dc}}$ and reference voltage, $\mathrm{V}_{\mathrm{dc} \text { ref }}$ .From this error $\mathbf{e}$ is estimated as (9)

$$
\boldsymbol{e}=V_{d c r e f}-V_{d c}
$$

Where, $\mathrm{V}_{\mathrm{dcref}}$ is considered as initial reference dc voltage and $\mathrm{V}_{d c}$ represents the recent system DC-Link capacitor voltage in volts measured across capacitance connected in VSI

Finally the error has been keep regulate by using PI technique .The regulated power, $\mathrm{P}_{\mathrm{rg}}$ can be expressed by the equation (10)

$$
P_{r g}=K_{P} e+K_{I} \int e d t
$$


The controller maintains the power in capacitor across VSI to the distribution grid system. The 3P SAPF current $\left(\mathrm{I}_{\mathrm{f}}^{*}\right)$ can be expressed as in equation (11)

$$
\left[\begin{array}{l}
i_{f a}{ }^{*} \\
i_{f b}{ }^{*} \\
i_{f c}{ }^{*}
\end{array}\right]=\sqrt{\frac{2}{3}}\left[\begin{array}{ccc}
\frac{1}{\sqrt{2}} & \frac{1}{\sqrt{2}} & \frac{1}{\sqrt{2}} \\
1 & -\frac{1}{2} & -\frac{1}{2} \\
0 & \frac{\sqrt{3}}{2} & -\frac{\sqrt{3}}{2}
\end{array}\right]\left[\begin{array}{l}
i_{f o}{ }^{*} \\
i_{f \alpha}{ }^{*} \\
i_{f \beta}{ }^{*}
\end{array}\right]
$$

\section{V.SIMULATION RESULTS FOR PI CONTROLLER BASED SAPF WITH P-Q THEORY}

The system ability and effectiveness of proposed solar photovoltaic interfaced Shunt Active Power Filter(SAPF) with PI controller is validated under 3 various cases like balanced input supply voltage with stable state load situation, balanced input supply voltage with unstable load condition and unbalanced supply voltage with unstable load situation.[30]

\section{CASE 1: Balanced input supply and stable state load}

Total Harmonic Distortion (THD) result analysis at prior compensation of connecting Solar Photovoltaic interlinked VSI-SAPF with PI Controller, source current total harmonic distortions levels in all three-phases (Iabc) values are $22.98 \%$, $21.68 \%$ and $20.93 \%$ respectively and the Load current magnitude values in Ampere are 23.78, 23.50, 23.75. Figure .5 shows the current THD value before connect solar photovoltaic interfaced VSI based SAPF with PI based instantaneous P-Q theory control technique [30].

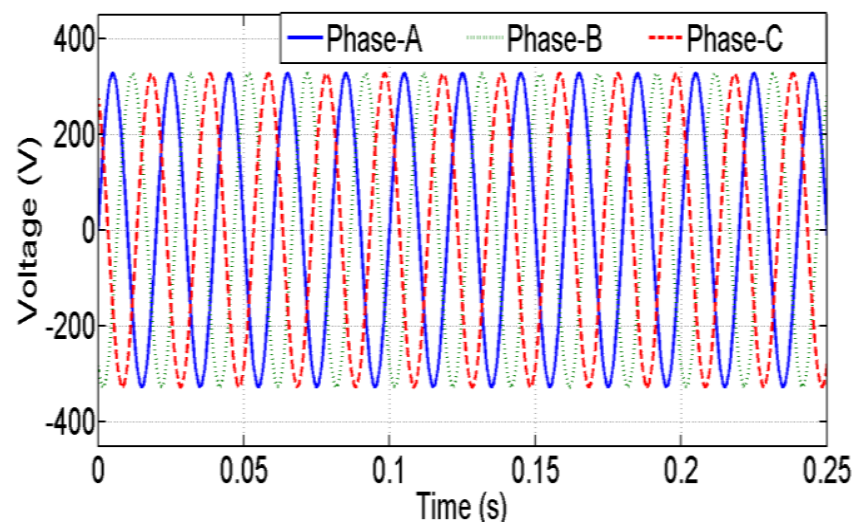

(a) 3 Phase Source voltages

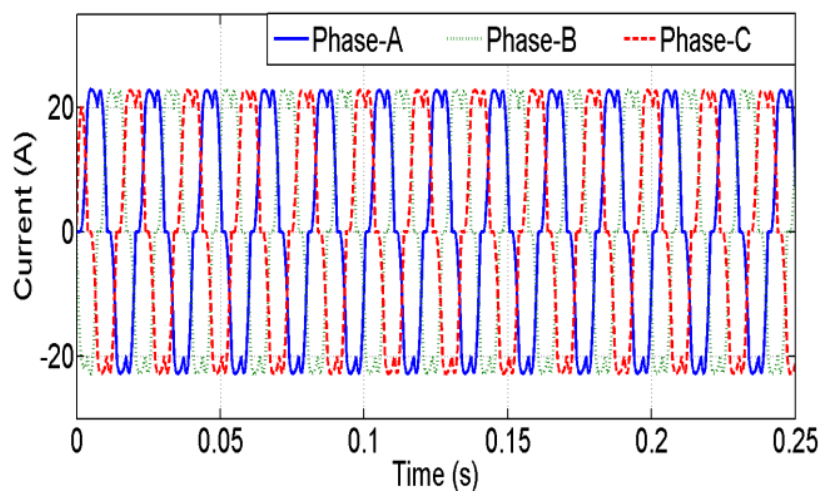

b) 3 phase Load currents before compensation

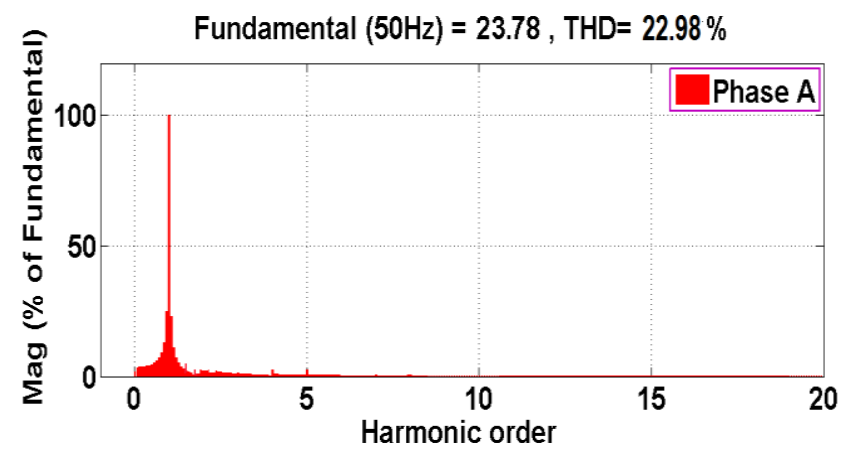

c) THD analysis prior SAPF compensation

Figure 5 shows the results of THD level before connecting SAPF with PI based instantaneous P-Q theory [31].

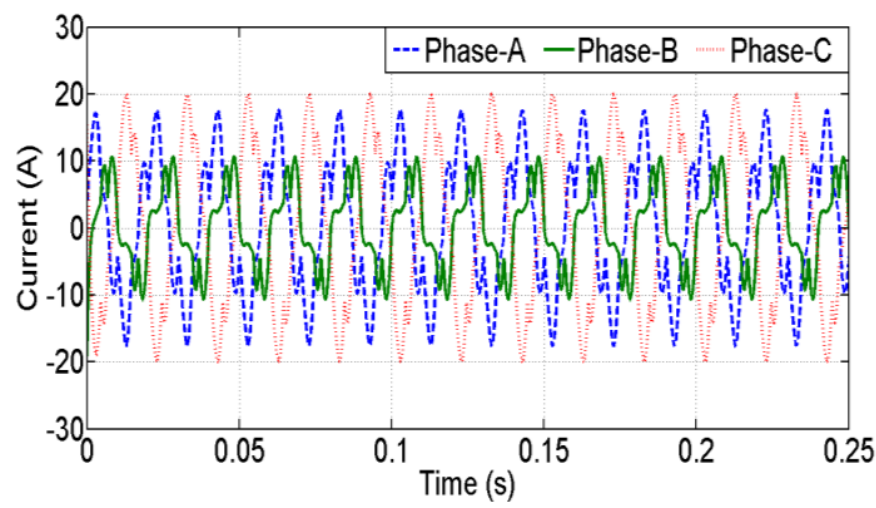

a)compensating SAPF current

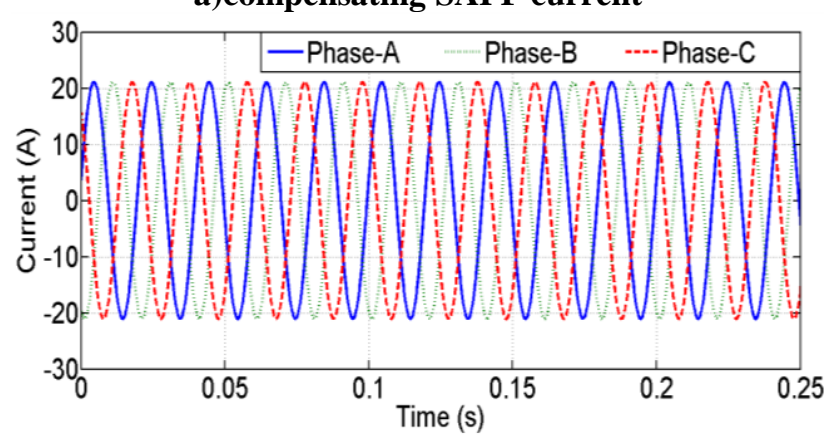

b) Compensated source current

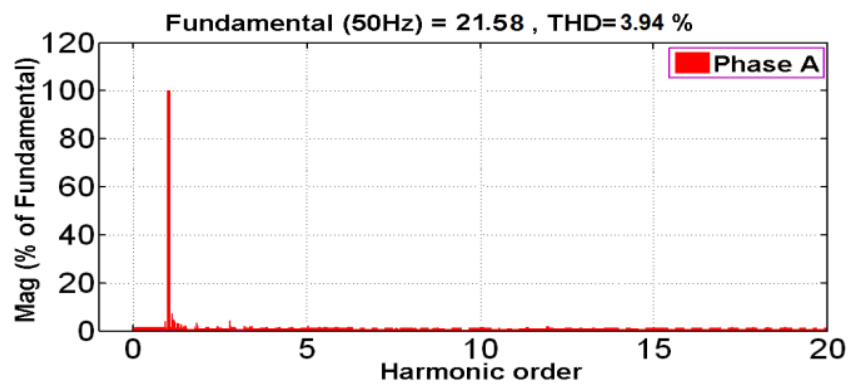

c) THD results analysis after connect SAPF Figure.6 THD analysis after connecting SAPF Figure .6 shows THD level after connecting SAPF filter with PI-based P-Q theory control technique.[17]

Published By Blue Eyes Intelligence Engineering \& Sciences Publication 


\section{CASE 2: Balanced input supply and unstable load}

The effectiveness of the solar photovoltaic shunt active power filter scheme is evaluated under balanced supply voltage with unstable load condition. THD analysis for prior and after compensating with SAPF under balanced supply voltage with unstable load situation is shown in Figure 7. At this load situation, the performance of shunt active power filter with the $p-q$ theory is validated under MATLAB/ simulation, the harmonic distortion level obtained in current prior compensation is $22.74(\%), 23.18(\%)$, and $22.57(\%)$, and it was decreased as $3.84(\%), 3.75(\%)$ and $3.94(\%)$ after compensation.
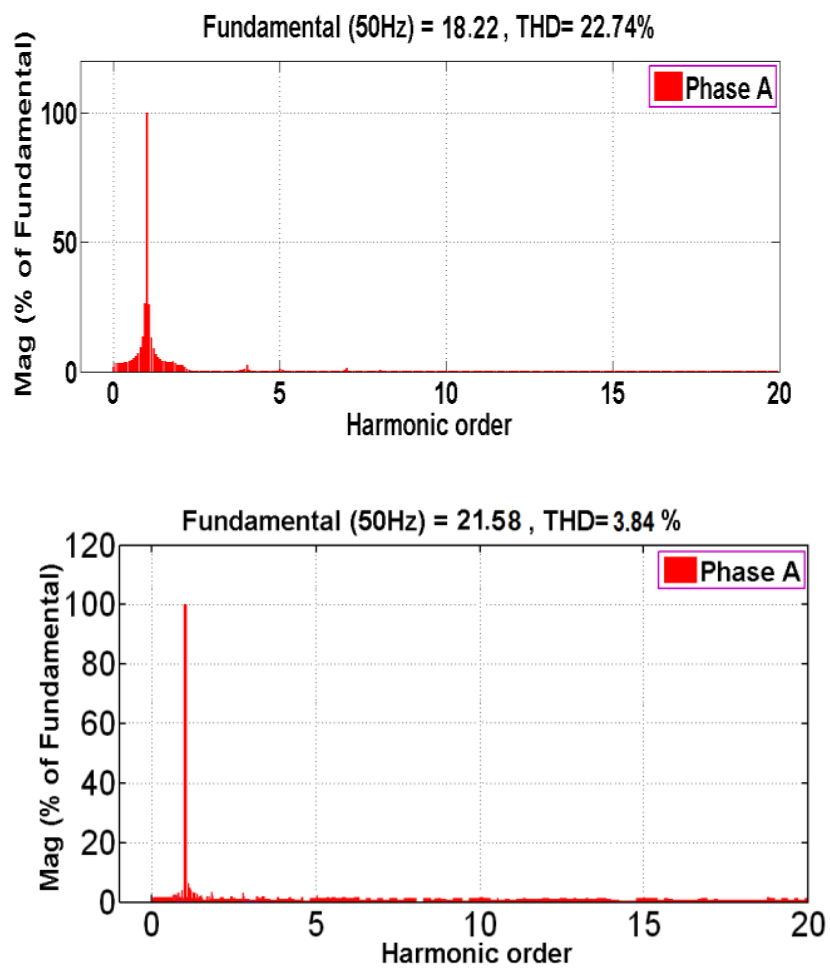

Figure 7 THD results for before and later compensating with SAPF

\section{CASE 3: Unbalanced input supply and unbalanced load}

The effectiveness of this proposed shunt active power filter is examined with unstable or unbalanced input supply voltage with non-linear (unbalanced) load condition. THD results for prior and after compensating under unbalanced input supply voltage with unstable load situation are shown in Figure 8. The efficiency and effectiveness of the shunt active power filter with the p-q theory is examined in MATLAB/simulation, the obtained harmonic level of the source current prior to compensation is $22.98(\%), 23.52(\%)$, and $22.68(\%)$, and it is reduced to $3.82(\%), 3.94(\%)$ and 3.72 (\%) after compensation.

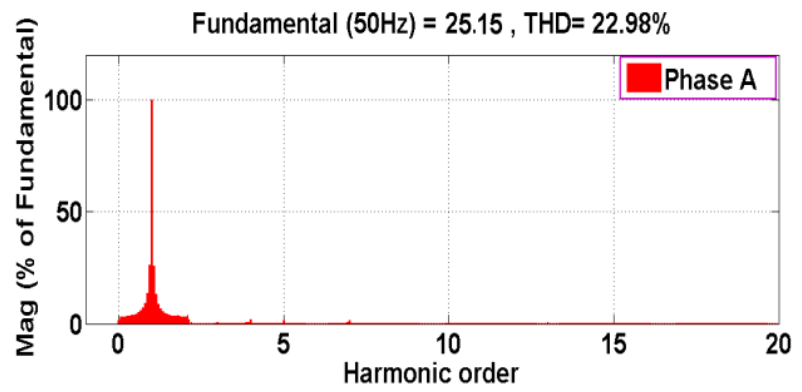

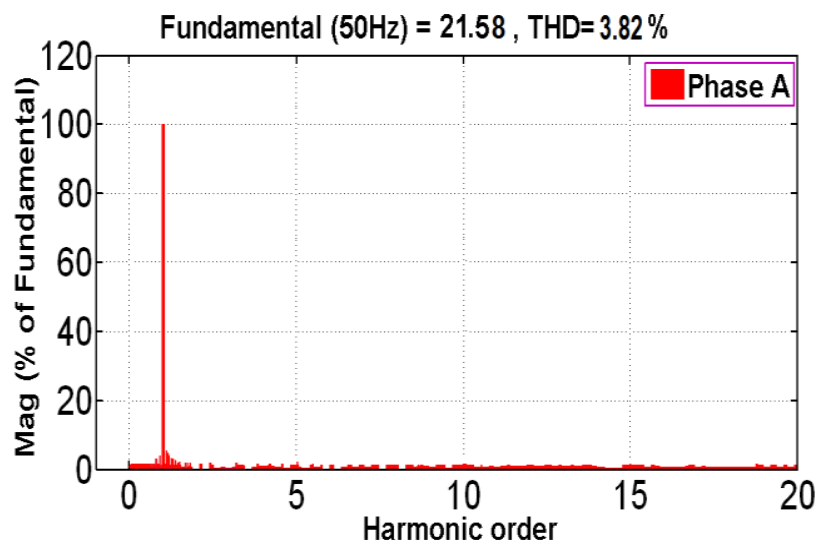

Figure.8 THD result analysis for before and after compensating with SAPF

The above Simulation results depicts that the proposed solar photovoltaic linked filter with PI controller employed to regulate the current harmonic components and other unbalanced non-linear load current as well as voltage variations in electric power distribution systems. Table 1 shows the detailed comparison of each phases based on simulation results after compensate control techniques. Figure 9 shows that the graphical comparative analysis of three cases.[17-23]

Table.1 Simulation results comparison

\begin{tabular}{|c|c|c|c|c|c|c|}
\hline \multirow{2}{*}{ Phase } & \multicolumn{6}{|c|}{ THD\% analysis before and after compensation } \\
\cline { 2 - 7 } & \multicolumn{2}{|c|}{ Case-1 } & \multicolumn{2}{|c|}{ Case-2 } & \multicolumn{2}{c|}{ Case-3 } \\
\hline A & 22.98 & 3.94 & 22.74 & 3.84 & 22.98 & 3.82 \\
& & & & & & \\
\hline B & 21.68 & 3.82 & 23.18 & 3.75 & 23.52 & 3.94 \\
\hline C & 20.93 & 3.75 & 22.57 & 3.94 & 22.68 & 3.72 \\
& & & & & & \\
\hline
\end{tabular}

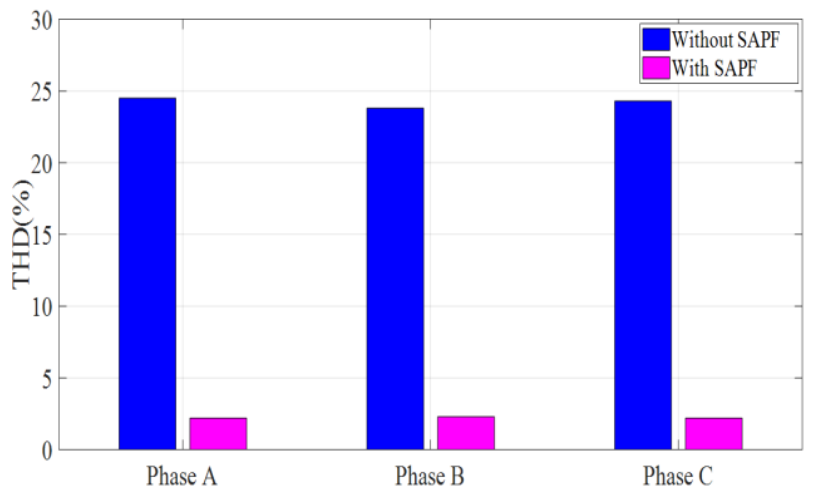

a)case 1 


\section{PV Based Grid System for Power Quality Enhancement using Instantaneous P-Q Theory}

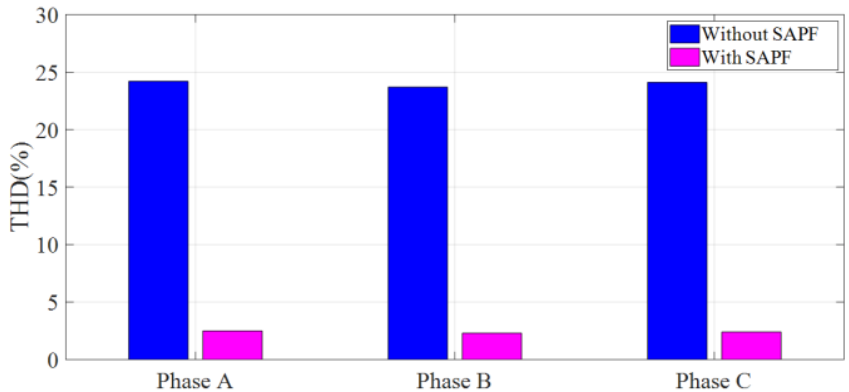

b)case 2

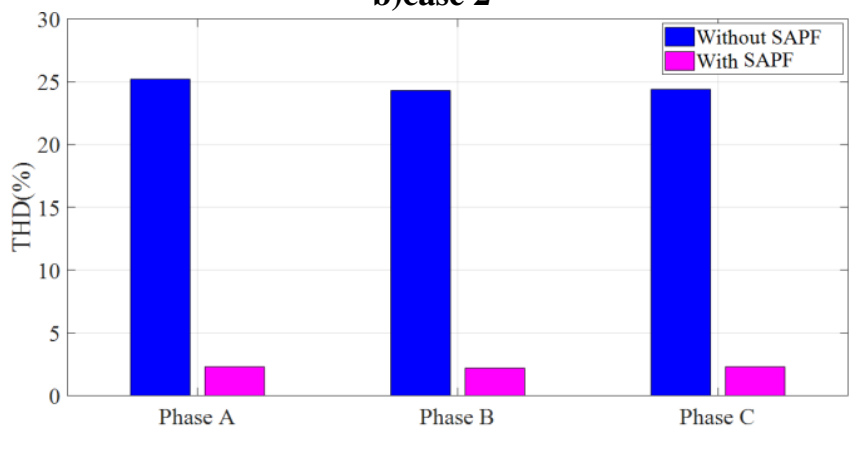

c)case 3

Figure 9 Graphical comparision of THD analysis for with and without connecting shunt-APF

\section{CONCLUSION}

This research work, current harmonic suppression and reactive power compensation based on shunt active power filter (SAPF) circuit besides with a perfect control scheme has been presented. Due to climatic changes, MPPT controller is employed to suck maximum power from $P V$ panel to maintain the efficiency. Furthermore, the shunt APF is mainly used to filter the harmonic content by a part of the power committed for harmonic filtering. An instantaneous p-q theory is used to generate the compensating current to maintain DC-Link voltage of the VSI. Reference voltage and DC Link voltage is controlled by PI controller. The effectiveness of the proposed system have been tested by using MATLAB/Simulink based on three cases such as balanced supply voltage with static load, unstable supply voltage , unstable load and unbalanced supply voltage with unstable non-linear load condition. Finally, the average THD level obtained from the three cases was observed to be $3.75 \%$.This obtained level is less when compared to IEEE standard. This controlling technique is much suitable for the harmonic elimation and also enhance the quality of power.

\section{REFERENCES}

1. El-Habrouk, M., Darwish, M., Mehta, P., "A review of Active power filters,"IEEE Proc. on Electric Power Applications, Vol.147, 2000, pp. 403-413.W.-K. Chen, Linear Networks and Systems (Book style).Belmont, CA: Wadsworth, 1993, pp. 123-135.

2. Ritesh Dash, PriyankaPaikray and S. C Swain M., "Active power filter for harmonic mitigation in a distributed power generation system," Innovations in Power and Advanced Computing Technologies (i-PACT), 2017, pp. 1-6.B. Smith, "An approach to graphs of linear forms (Unpublished work style)," unpublished.

3. S.Devassyand B.Singh, "Design and Performance Analysis of Three-Phase Solar PV Integrated UPQC," IEEE Transactions on Industry Applications, Vol. 54, No. 1, 2018, pp. 73-81.

4. Mikkili, S., Panda, A.: 'Real-time implementation of PI and fuzzy logic controllers based shunt active filter control strategies for power quality improvement', International Journal of Electrical Power and Energy Systems, 2012, 43, pp. 1114-1126.

5. Liu Cong, Dai Ke, Chen Xinwen, He Yuqing and Lu Pingjiang "Selective harmonic suppression strategy by SAPF in power distribution system", The Journal of Engineering, Vol. 2017, No. 13, 2017, pp. 1610-1613.

6. Suresh, K P \& Ramesh, S 2019, 'Grid-Interconnected Solar Photovoltaic System for Power Quality Improvement Using Extended Reference Signal Generation Strategy', Journal of Testing and Evaluation. ISSN: 0090-3973

7. M. Vijayakumar and S. Vijayan, Photovoltaic interfaced three-phase four-wire unified power quality conditioner with extended reference current generation scheme, Australian J. Electrical Electron. Eng. Vol. 12, 2015, pp. 94-112.

8. Zhen Yu Zhao,MasayoshiTomizuka, and Satoru Isaka 'Fuzzy Gain Scheduling of PID Controllers', IEEE Trans. on system man and cybernetics, Vol. 23, 1993, pp. 1392-1398

9. G.J. Kish., J.J. Lee.,P.W. Lehn.: 'Modelling and control of photovoltaic panels utilising the incremental conductance method for maximum power point tracking', IET Renewable Power Generation, Vol. 6, 2011, pp.259-266.

10. P.K. Ray,P.S. Puhan and G.Panda"Real time harmonics estimation of distorted power system signal,"International Journal of Electrical Power and Energy Systems, Vol.75, 2016, pp. 91-98

11. Gunjan Gupta and Wilfred Fritz, "Control algorithms for a three-phase Shunt compensator- A comparative study ," 3rd International Conference on Computational Intelligence \& Communication Technology (CICT), 2017, pp. 1-5

12. Belaidi, R, Haddouche, A, Fathi, M, Larafi, MM \& Chikouche, A 2011, 'Improvement of the electrical energy quality using a Shunt Active Filter supplied by a photovoltaic generator', Energy Procedia, pp.522-530.

13. Araujo Ribeiro, RL, Azevedo, CC \& Sousa, RM 2012, 'A robust adaptive control strategy of active power filters for power-factor correction, harmonic compensation, and balancing of nonlinear loads,' IEEE Transactions on Power Electronics, vol. 27, no. 2, pp. 718-730.

14. Akagi, H 1996, 'New trends in active filters for improving power quality', In Power Electronics, Drives and Energy Systems for Industrial Growth, Proceedings of the International Conference on IEEE, pp. 417-425.

15. Acuna, P, Moran, L, Rivera, M, Dixon, J \& Rodriguez, J 2014, 'Improved active power filter performance for renewable power generation systems', IEEE transactions on power electronics, vol. 29, no. 2, pp. 687-694.

16. Tareen, A, SaadMekhilef, Seyedmahmoudian, M \& Horan, B 2017, 'Active power filter (APF) for mitigation of power quality issues in grid integration of wind and photovoltaic energy conversion system', Renewable and Sustainable Energy Reviews, vol. 70, pp.635 -655..44, no.1, pp.179-191

17. Srinath,S, Poongothai,S \& Aruna,T 2017, 'PV Integrated Shunt Active Filter for Harmonic Compensation', Energy Procedia, vol. 117, pp.1134 $-1144$.

18. Peng, FZ 1998, 'Application issues of active power filters', IEEE Ind. Appl. Mag.,vol. 4, pp. 21-30.

19. Patjoshi, RK, Kolluru, VR \& Mahapatra, K 2017,'Power quality enhancement using fuzzy sliding mode based pulse width modulation control strategy for unified power quality conditioner', Electrical Power and Energy Systems, vol. 84, pp. 153-167

20. Mehrasa, M, Pouresmaeil, E, Zabihi,S, Rodrigues, EMG, \& Catalão, JPS 2016, 'A control strategy for the stable operation of shunt active power filters in power grids', Energy, vol. 96, pp.325 -334.

21. Lincy, Luciana M., and Kumar R. Senthil. "Comparison Analysis of Fuzzy Logic and Anfis Controller for Mitigation of Harmonics." 2018 4th International Conference on Electrical Energy Systems (ICEES). IEEE, 2018.

22. Sarasvathy, K., M. Lincy Luciana, and R. Senthil Kumar. "Comparison of sine, hysteresis, SVPWM and predictive PWM techniques for shunt active power filter." 2017 IEEE International Conference on Electrical, Instrumentation and Communication Engineering (ICEICE). IEEE, 2017.

23. Poornaselvan K.J., Gireesh Kumar T., Vijayan V.P. Agent based ground flight control using type-2 fuzzy logic and hybrid ant colony optimization to a dynamic environment International Conference on Emerging Trends in Engineering and Technology 4579922 pp-343 $-348,2018$

Published By:
Blue Eyes Intelligence Engineering


24. Vijayakumari V., Suriyanarayanan N. Survey on the detection methods of blood vessel in retinal images European Journal of Scientific Research,vol 68 issue 01 pp 83-92,2012

25. Kumar P.S., Gayathri R., Senthamarai C., Priyadharshini M., Fernando P.S.A., Srinath R., Kumar V.V. Kinetics, mechanism, isotherm and thermodynamic analysis of adsorption of cadmium ions by surface-modified Strychnos potatorum seeds Korean Journal of Chemical Engineering .vol 29 issue 12 pp 1752- 1760,2012

26. Bhuvaneswari K., Rauf H.A., Edgelet based human detection and tracking by combined segmentation and soft decision 2009 International Conference on Control Automation, Communication and Energy Conservation, 5204487 INCACEC 2009

27. Jameer Basha A., Palanisamy V., Purusothaman T. Efficient multimodal biometric authentication using fast fingerprint verification and enhanced iris features, Journal of Computer Science Vol 7 issue 5 pp 698706,2011

28. Punithavathani D.S., Sankaranarayanan K. IPv4/IPv6 transition mechanisms, European Journal of Scientific Research vol 34 ,issue 1,PP 110-124,2009

29. Sreeja N.K., Sankar A. Pattern matching based classification using Ant Colony Optimization based feature selection, Applied Soft Computing Journal VOL 31 issue 2818 PP 91-102,2015

30. P. Chandra Babu Naidu, C. Kamal Basha, K.Rajangam, D.Chinnakullay Reddy., "Estimation and Mitigation of Power System Harmonics with Kalman Filter Algorithm", Journal of Convergence Information Technology(JCIT) Volume11, Number5,pp122-132,2016.

31. Rajangam, K., Ravi Kumar M, C. Kamal Basha, P.Chandra Babu Naidu., "Design of Fuzzy Logic MPPT Controller of a Solar PVSystem under Weather Changing Conditions", International Journal of Engineering Research And Management (IJERM) Vol.3, No.7, pp. 110-117, 2016

\section{AUTHORS PROFILE}

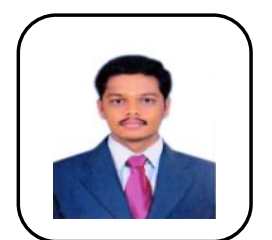

K. P. Suresh received UG degree from M.Kumarasamy college of Engineering, Karur, Tamilnadu. He received PG degree in the stream of Power Electronics and Drives from K.S.R.College of Engineering, Tiruchengode, Tamilnadu. $\mathrm{He}$ attaneded more number of conferences and presented more papers in the field of power electronics and renewable energy sources. Currently he is working as a Assistant professor in Sri Krishna College of Technology, Coimbatore, Tamilnadu. His area of interest is in the field of Power quality, Renewable Energy Sources and Intelligent Techniques

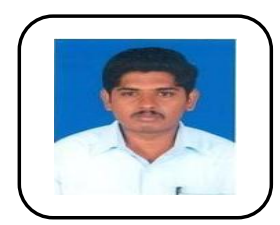

S. Ramesh received UG degree from Bharathiar University, Coimbatore, Tamilnadu in the year of 2000. He received PG degree in the stream of Power Systems from Annamalai University, Chidambaram, Tamilnadu in the year of 2004.He completed his Ph.D in Electrical Engineering from Anna University, Chennai, Tamilnadu in the year of 2011. He attended various international conferences and published so many papers in international journals. His area of interest is Power Systems, Renewable Energy Sources, Soft Computing Techniques and Artificial Intelligent controllers. He is currently working as a Professor\& Head in Electrical and Electronics Engineering Department at K.S.R.College of Engineering, Tiruchengode, Tamilnadu.. He is in teaching field for past 15 Years of experience and also guides research scholars under Anna University, Chennai. 